\title{
Um modelo sistémico de gestão da informação: da flexibilidade organizacional à interoperabilidade do sistema ${ }^{1}$
}

\author{
Maria Manuela Pinto \\ Universidade do Porto, Faculdade de Letras, CIC.DIGITAL Porto, Portugal \\ mmpinto@letras.up.pt
}

DOI: https://doi.org/10.26512/rici.v12.n1.2019.11015

Recebido/Recibido/Received: 2018-05-05

Aceitado/Aceptado/Accepted: 2018-07-03

Resumo: Introduz-se o Modelo de Gestão do Sistema de Informação Ativa e Permanente (MGSI-AP), resultado de uma investigação que discutiu conceitos e perspetivas em torno da Gestão da Informação, posicionou-a como área transversal e aplicada em Ciência da Informação, com o foco no(s) fluxo(s) infocomunicacional(ais), atendendo de forma particular aos que ocorrem em meio digital, no contexto de uma instituição complexa - a universidade pública portuguesa e respetivos serviços de informação. A universidade é perspetivada numa dupla faceta sistémica e, consequentemente, complexa, isto é, entre o sistema organizado formal e o sistema combinatório de feição loosely coupled. Apresenta-se um dos eixos da operacionalização da investigação realizada e do modelo desenvolvido. Nele se destaca a estreita ligação da Gestão da Informação à área de estudos da Produção Informacional, enquadrada por uma proposta teórico-metodológica e de modelação operacional que convergem para uma definição de Gestão da Informação e a conceção de uma Matriz/Cubo de Componentes e Variáveis em análise.

Palavras-chave: Gestão da informação. Modelo de Gestão do Sistema de Informação Ativa e Permanente. sistema de informação. universidade.

\section{Un Modelo Sistémico de Gestión de la Información: de la flexibilidad organizativa a la interoperabilidad del sistema}

Resumen: El trabajo introduce el Modelo de Gestión de un Sistema de Información Activo y Permanente (MGSI-AP), resultado de una investigación que discutió conceptos y perspectivas sobre la Gestión de la Información, posicionándola como un área transversal y aplicada en Ciencia de la Información, enfocada en el flujo(s) infocomunicacional(es), prestando especial atención a los que ocurren en los medios digitales, en un contexto institucional complejo - la Universidad pública portuguesa y los servicios de

\footnotetext{
1 Texto originado de palestra proferida no XI Workshop Internacional em Ciência da Informação, Faculdade de Ciência da Informação e Programa de Pós-graduação em Ciência da Informação da Universidade de Brasília. Brasília, 12-15 de setembro de 2016.
} 
información relacionados. Se perspectiva la Universidad en una doble y compleja faceta sistémica, entre el sistema formal organizado y el sistema combinatorio de características loosely coupled. Se presenta uno de los ejes de operacionalización de la investigación realizada y modelo desarrollado. Aquí se destaca la estrecha conexión entre la Gestión de la Información y el área de estudio de la Producción de Información, enmarcada por una propuesta teórico-metodológica y la formulación de modelos operativos que convergen a una definición de Gestión de la información y diseño de una Matriz / Cubo de Componentes y Variables en análisis.

Palabras-clave: gestión de la información. Modelo de Gestión de un Sistema de Información Activo y Permanente. sistema de información. universidad.

\section{A Systemic Information Management Model: from organizational flexibility to interoperability of the} system

Abstract: The paper introduces the Active and Permanent Information System Management Model (MGSI-AP). It results from an investigation that discussed concepts and perspectives about Information Management, positioning it as a transversal and applied area within Information Science, focused on info communicational flow, in a complex institutional context - the Portuguese public University and related information services. The University is assumed in a complex and systemic double facet, between the formal organized system and the loosely coupled combinatory system. Here is presented one of the operationalization axes of the performed research and model. It highlights the close connection between Information Management and the area of studies of Information Production, framed by a theoretical-methodological proposal and operational modeling, which converge to an Information Management definition and the design of a Matrix of Components and Variables under analysis.

Keywords: Active and Permanent Information System Management Model. information management. information system. university.

\section{Introdução}

O desafio que nos foi lançado em torno dos Documentos Digitais: Gestão, Preservação e Acesso poderia ter passado pela abordagem da preservação em meio digital, os seus problemas, desafios e estratégias no quadro de reflexões como, por exemplo, a que desenvolvemos em torno do PRESERVMAP (PINTO, 2009), num período em que se apelava à consciencialização e à ação.

De facto, em 2007/2009 centrámo-nos no mapeamento do que vinha acontecendo neste domínio desde finais do século $\mathrm{XX}$, na discussão dos conceitos de preservação e conservação e, sobretudo, em posicionar a problemática da preservação da informação no âmbito da Gestão da Informação (GI), com uma amplitude que procurava abarcar todo o ciclo de gestão do fluxo infocomunicacional e consequente produção informacional, integrando nessa aproximação sistémica quer a informação registada em suportes tradicionais quer em meio digital.

Os desenvolvimentos que se seguiram conduziram-nos a uma proposta de Modelo de Gestão do Sistema de Informação Ativa e Permanente (MGSI-AP), resultado de uma investigação que discutiu conceitos e perspetivas em torno da Gestão da Informação (GI), posicionou-a como área transversal e aplicada em $\mathrm{Cl}$ e com o foco no(s) fluxo(s) infocomunicacional(ais), atendendo de forma particular aos que ocorrem em meio digital, no contexto de uma instituição complexa - a universidade pública portuguesa - e respetivos serviços de informação (PINTO, 2015). 
Para a presente reflexão selecionamos um dos eixos da operacionalização da investigação realizada e do modelo desenvolvido. Nele se destaca a estreita ligação da GI à área de estudos da Produção Informacional (PInf), no que convoca em termos de organicidade, de memória, dos vários contextos e meio ambiente em que ocorre a génese e o fluxo infocomunicacional, isto é, do quadro sistémico de atuação nos seus três componentes Institucional/Organizacional, Informacional e Tecnológico - e respetiva matriz de variáveis em análise, cuja compreensão alicerça quer uma abordagem investigativa, quer de aplicação/operacionalização.

Componentes sistémicos e matriz de variáveis são, pois, fundamentais para abordar a problemática do desafio digital, enquadrando-o, desde logo, por uma perspetivação plurifacética do(s) contexto(s) de produção e fluxo informacional e pelo reconhecimento das configurações sistémicas que lhe são inerentes.

\section{0 contexto de uma investigação em Gestão da informação na Universidade}

A análise da produção científica mostrou-nos que os estudos em torno da Universidade se vêm centrando na abordagem histórica, na educação e ensino, na sociologia, na psicologia e na gestão das Organizações, e, crescentemente, em torno da avaliação e da gestão da qualidade, a par da inovação, verificando-se a perspetivação do Ensino Superior no quadro dos diversos sistemas, (re)estruturações e crises.

Apesar de nos encontrarmos em plena Era da Informação, o foco no Ensino Superior, e muito particularmente na Universidade, pela perspetiva informacional e do fenómeno infocomunicacional neste tipo de entidade (informação e respetiva gestão na universidade) é, na verdade, residual, quer a nível temático, quer da realidade em foco, não existindo estudos sistemáticos a este nível.

As análises centram-se, sobretudo, na organização/gestão, nas tecnologias e no tradicional serviço de informação - Arquivo, Biblioteca, Centro de Documentação e Museu² -, respetivos acervos, serviços e gestão, partindo ou da perspetiva arquivística, ou biblioteconómica, ou documentalista, ou museológica, as quais enformam e delimitam o âmbito analisado.

Estes estudos focam, maioritariamente, a biblioteca especializada, corporizada na Biblioteca Universitária, no percurso histórico ${ }^{3}$, respetivos acervos e recursos informacionais, serviços disponibilizados, caraterização de utilizadores e utilização das Tecnologias da Informação e Comunicação (TIC), funções institucionais e competências dos profissionais.

Situação similar, mas com menor produção, ocorre ao nível dos museus universitários, apesar de institucionalmente menos estruturados mas muito ligados à história da Ciência, mantendo sempre que possível a coexistência de um centro de documentação/biblioteca e arquivo histórico do Museu.

\footnotetext{
${ }^{2}$ Cf. produção bibliográfica em Pinto (2015, p. 589-590).

3 Vejam-se, a título de exemplo, as comemorações dos 500 anos da Biblioteca da Universidade de Coimbra que decorreram de fevereiro de 2013 a fevereiro de 2014.
} 
No âmbito dos Arquivos Universitários, é de destacar, sobretudo a nível internacional, os estudos sobre estes serviços, como acontece em Espanha e no Brasil, ou abrangendo os "Records Management" nos "Colleges", no universo anglo-saxónico, sendo de referir, em Portugal, o início de uma tentativa de valorização do seu estudo e de viragem paradigmática, com a realização da primeira Conferência sobre Arquivos Universitários, em 1997 ${ }^{4}$, e as publicações que se seguiram (RIBEIRO, 1999; RIBEIRO e FERNANDES, 2001), nomeadamente as decorrentes de projetos desenvolvidos na Universidade do Porto (U.Porto), no âmbito do programa PRAXIS XXI, com uma abordagem que indicia a sua perspetivação pelo então emergente campo científico da $\mathrm{Cl}$.

Ao nível dos Centros de Documentação confirma-se o seu direcionamento para áreas científicas especializadas e ligação a Unidades de Investigação e Desenvolvimento (UI\&D5), a par da abrangente disseminação dos Centros de Documentação Europeia pelas universidades portuguesas, maioritariamente nas bibliotecas universitárias, estudados por Terra (2009) no âmbito das políticas, mediadores e utilizadores de informação europeia.

Mais recentemente, destacam-se estudos com o foco na qualidade e avaliação do desempenho de bibliotecas e serviços de informação (MELO, 2005, 2012), na participação no processo de criação e comunicação da ciência - informação científica e respetivo acesso, disseminação e uso (BORGES, 2006), nos estudos bibliométricos e de comportamento informacional, nomeadamente de literacia informacional, na participação no processo de ensino-aprendizagem, nos repositórios institucionais, sua criação, gestão e políticas, entre outros temas e iniciativas com eles relacionados, nomeadamente as que envolvem aspetos como o acesso, a organização, a comunicação, o uso e a aplicação da informação científica e técnica.

Se sob o impacto da expansão tecnológica vínhamos, desde os finais dos anos 90 , operando e contribuindo para a reflexão e afeiçoamento teórico-conceptual sob um novo paradigma - cientifico-informacional - em $\mathrm{Cl}$ (Quadro 1), foi nosso propósito perceber este contexto e desenvolver uma proposta em GI que conciliasse o duplo foco na dimensão diagnóstico e na dimensão ação, centrando-se esta não apenas na investigação realizada mas também numa visão prospetiva que sustentou o desenvolvimento de um modelo para a operacionalização da Gl em contexto universitário.

\footnotetext{
${ }^{4}$ Conferência sobre Arquivos Universitários (1999) e, no caso da U. Porto, Ribeiro (1999).

${ }^{5}$ Encontram-se referências bibliográficas relativas ao papel a desempenhar pelas bibliotecas, por exemplo em Laboratórios Associados (cf. MEIRA, 2008).
} 
Quadro 1 - Conceitos Chave

\begin{tabular}{|c|c|}
\hline \multicolumn{2}{|c|}{ CONCEITOS CHAVE } \\
\hline Paradigma Técnico e Custodial & Paradigma Cientifico-informacional \\
\hline Arquivística/Arquivologia & \multirow{3}{*}{ Ciência da Informação } \\
\hline Biblioteconomia & \\
\hline Ciências Documentais & \\
\hline Arquivo & \multirow{3}{*}{ Sistema de Informação } \\
\hline Colecção & \\
\hline Fundo & \\
\hline Documento de arquivo & \multirow{2}{*}{ Informação } \\
\hline Documento de biblioteca & \\
\hline Artefacto & Mentefacto \\
\hline Suporte & $\begin{array}{c}\text { "Meio"/infra-estrutura material e/ou } \\
\text { tecnológica } \\
\text { [onde se encontra e/ou através do qual acedemos à } \\
\text { informaçẫo] }\end{array}$ \\
\hline
\end{tabular}

Fonte: Pinto (2009).

Seja na perspetiva do suporte administrativo e tecnológico, seja sob a feição de serviço especializado, relevaram-se e analisaram-se Bibliotecas, Arquivos, Centros de Documentação e Museus, assim como os emergentes serviços de Informática e/ou de Gestão da Informação. Enunciaram-se os desafios que, de forma particular, Ihes eram colocados pelo meio digital, não esquecendo o processo da institucionalização destes serviços na Universidade em Portugal e um percurso em que se identifica a influência europeia/francófona e a influência anglosaxónica na área comummente designada por BAD (Biblioteconomia, Arquivística e Documentação, a que se junta a Museologia), ou, ainda, como Ciências Documentais, e que acaba por confluir na Ciência da Informação (Cl) e, nesta, tocar uma Gl que, na nossa perspetiva, foca a génese e o fluxo infocomunicacional e que afirma a sua feição transversal e marcadamente aplicada como área de estudos. Salienta-se na representação infra (Figura 1) o papel e importância que conferimos à Gl e à interação e interseção permanente que ocorre entre esta e as restantes áreas de estudos em $\mathrm{Cl}$, designadamente, a Produção informacional (PInf), em foco nesta reflexão, a Organização e Representação da Informação (ORI) e o Comportamento Informacional (CInf) (PINTO, 2015, p. 546).

Importa, por último, destacar que esta abordagem constituiu uma segunda fase de um percurso investigativo que considerou: 1) uma $\mathrm{Cl}$ transdisciplinar que constitui um estádio epistemológico evolutivo que resulta da interação e integração de disciplinas práticas como a Arquivística, a Biblioteconomia e a Documentação, e que mantém “[...] a sua vocação interdisciplinar, que ocorre por níveis de proximidade, acontecendo, em primeiro lugar, no campo emergente das Ciências da Informação e Comunicação e, em seguida, no campo mais vasto das Ciências Sociais aplicadas" (SILVA, 2007) ; 2) mas que também explorou um conceito caro aos arquivistas - o do contexto da produção informacional - atendendo, assim, à importância da Organicidade, não apenas como sinónimo de discurso jurídico-administrativo, mas apontando para a totalidade da produção/criação (o todo informacional orgânico, pela via 
formal e informal) e fazendo parte de um trinómio que urgia equilibrar - a Organicidade (a estrutura produtora), a Funcionalidade (o serviço/uso da informação) e a Memória (identidade e património).

Figura 1 - Dimensão científica: a Gl em Cl

GI uma área de estudos transversal, de interação e interseção permanente com a PInf, ORI e CInf

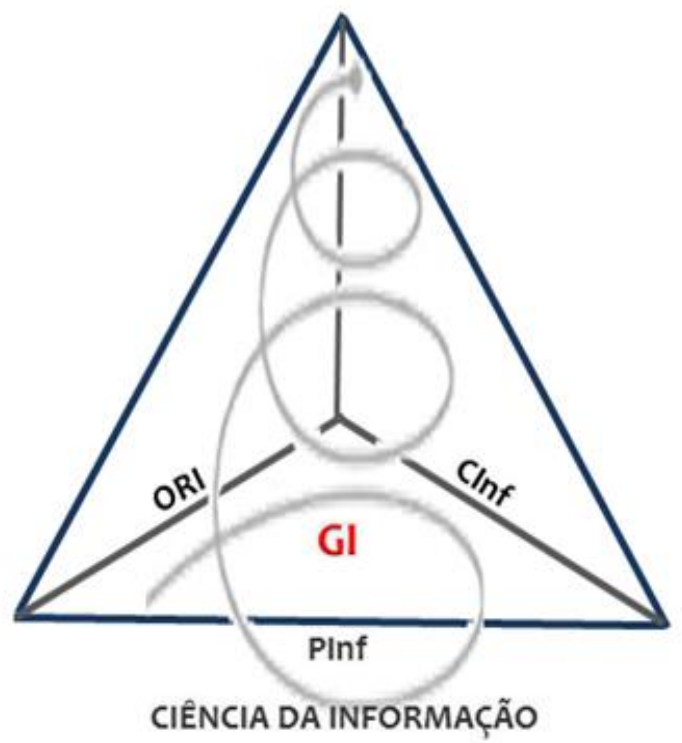

Daqui decorreu a análise detalhada dos conceitos de "Instituição" e de "Organização" que se revelou fundamental para, depois, mapearmos o percurso da Universidade pública portuguesa e compreendermos a "ação estruturante" que, ao longo dos séculos, vem modelando o sistema de informação organizacional, repercutindo-se na respetiva gestão.

Se a Universidade se institui como o "lugar" de reunião dos mestres e seus discípulos em busca do conhecimento, a contemporaneidade proporciona o olhar para a Instituição que alavanca a economia do conhecimento, e para a Organização que precisa de se "organizar e gerir" para perdurar, justificando a coexistência, em complementaridade, destes dois conceitos. Assim, no continuum de uma existência secular, a problemática da Gestão na Universidade exige, hoje, rápidas respostas a um ambiente caracterizado pela globalização e uma clara afirmação do seu quadro de valores como Instituição, integrando, através do seu dispositivo estrutural de governo / gestão, o conceito de Organização (envolvendo, entre outros aspetos, a estrutura, os papéis e os comportamentos).

A definição identitária da Universidade e o seu posicionamento em termos de decisão e de ação acabam, desta forma, por se refletir na sua maior ou menor capacidade de adaptação e/ou flexibilização face à rapidez das mudanças, sendo também determinante o papel da Memória que constrói e acumula, seja tangível ou intangível, encontre-se registada em suportes tradicionais ou em meio digital. 
Esta é uma Memória que não só reflete a unidade do todo institucional mas também as várias autonomias, a liberdade intelectual, a independência ética e científica que, no quadro sistémico em que se situa a Universidade, são indissociáveis dos seus atores e dos percursos que desenvolvem na ação quotidiana de ensinar, produzir, disseminar e transferir conhecimento, bem como das inerentes atividades de suporte, alinhando-se a instituição e o seu dispositivo de governação.

Adota-se, assim, uma perspetiva sistémica e dinâmica para captar a totalidade do fenómeno infocomunicacional num domínio institucional sob a pressão das mudanças gestionárias organizacionais, decorrentes das políticas da governação nacional e europeia e do ambiente global da Era da Informação, assumindo e procurando delimitar a GI como área de estudos em $\mathrm{Cl}$.

\section{Do sistema aos componentes sistémicos do modelo}

A Teoria Geral dos Sistemas constituiu o referente interpretativo orientador da investigação realizada e, como se constatou, a terminologia relacionada com a temática em estudo está fortemente marcada pelo pensamento sistémico sendo visível a extensão e diversidade de aplicação a partir de termos como: Sistema Social; Sistema Organizacional (SO); Sistema Jurídico-administrativo (SJA); Sistema de Informação (SI); Sistema de Informação Organizacional (SIO); Sistema de Arquivo (SA); Sistema Tecnológico de Informação (STI); Sistema(s) de Gestão (SG); Subsistema de Gestão de Informação (SsGI); Subsistema de Gestão do Conhecimento (SGC); Sistema(s) específico(s) da "área de negócio"; Sistema Educativo (SE); Subsistema de Ensino Superior (SsES), Sistema Científico (SC), Sistema Científico e Tecnológico Nacional (SC\&TN), Sistema de Inovação (SIn), Sistema de Investigação, Desenvolvimento e Inovação (SIDI), etc.

No âmbito da Gestão, Chiavenato define Sistema como um conjunto de coisas ou combinações de coisas ou partes, formando um todo complexo ou unitário (CHIAVENATO, 2000 , p. 545$)^{6}$, sendo-lhe inerente a ideia de conjunto de elementos interdependentes e interatuantes ou conjunto de unidades combinadas que formam um todo.

Por sua vez, Fernanda Ribeiro (2004a) constata que, no domínio da Informação, verifica-se nos diversos autores uma clara preferência pelas abordagens e modelos de aplicação sistémica, de forma especial ao nível da conceção de sistemas (tecnológicos) de informação, partindo do pensamento de Jean-Louis Le Moigne (CARVALHO, 2000), mas também no domínio da Biblioteconomia (MOLINA CAMPOS, 1995) e da própria Arquivística (ARÉVALO JORDÁN, 1987; JARDIM, 1995; SILVA [et al.], 1999 e SILVA e RIBEIRO, 2002).

O conceito Sistema foi introduzido em 1968 pelo biólogo Ludwig von Bertalanffy e associado à "Teoria Sistémica" (BERTALANFFY, 1973), verificando-se hoje o seu uso de forma intensa e extensiva nas diversas ciências, tecnologias e domínios da atividade humana e social (SILVA, 2006, p. 161).

\footnotetext{
6 Cf. outras obras e autores de referência como: Chiavenato (1999); Stoner e Freeman (1999); Hampton (1992).
} 
Bertalanffy recusa a visão cartesiana do universo e a divisão em diferentes áreas (física, biologia, psicologia), foca a evolução das ciências e as suas consequentes especializações, e parte da abordagem orgânica da biologia, assumindo que o organismo (sistema) é um todo maior que a soma das suas partes (elementos). Atende, assim, à nova diversidade "contingencial" acolhendo-a por uma perspetiva mais geral que, ao nível organizacional, permite abarcar fatores como o grau de estabilidade no meio ambiente, os fatores culturais, a dimensão, a longevidade, ou a diversificação do "produto".

Com a formulação da Teoria Geral dos Sistemas, Bertalanffy propõe o estudo global de sistemas, envolvendo todas as suas interdependências e reunindo todos os seus elementos por forma a constituir uma unidade funcional mais ampla, na qual seriam desenvolvidas qualidades não passíveis de encontrar nos componentes isolados.

A noção operatória de Sistema é, pois, um conceito abstrato e amplo podendo configurar-se como um Sistema Institucional (SInst), um Sistema Organizacional (SO) um Sistema de Informação Organizacional (SIO) ou um Sistema Tecnológico de Informação (STI), implicar, ou não, a interação com o ambiente, ser reconhecido pela estrutura dinamicamente duradoura que evolui no tempo e que se complexifica ao longo do mesmo, isto é, pode ser definido enquanto estrutura, mas não se confundindo com ela (a estrutura define os limites do sistema), ou reconhecido por comportamentos, resultar de combinações de comportamentos ou constituir um conjunto de ações de "prossecução" na procura da concretização de um objetivo.

Elementos (da estrutura) ou unidades (combinadas) e relações ou comportamentos, definem um todo unitário que reage globalmente, isto é, um estímulo sobre qualquer dos elementos/unidades afeta o todo, dadas as relações/interligações existentes entre as partes componentes.

\begin{abstract}
[Se] por um lado, o sistema torna-se uma unidade na multiplicidade dos seus componentes; por outro, as partes perdem, no sistema, a sua individualidade, tornando-se igualmente essenciais na formação da unidade», o que permite compreender que embora os elementos de um sistema percam a sua individualidade, porém estes são fundamentais para a formação da unidade como um todo, ou seja, o sistema como uma estrutura complexa depende da relação e inter-relação entre os seus elementos para poder existir (SILVA e RIBEIRO, 2002, p. 96).
\end{abstract}

No quadro da $\mathrm{Cl}$, a sua adoção ocorre em linha com o pensamento de Piero Mella segundo o qual: o Sistema "não é uma estrutura, mas possui ou integra uma estrutura duradoura que apresenta um fluxo de estados no tempo e não existe na realidade mas é concebido como tal por qualquer observador que atribua significado aos estados ou às situações, assumidos por uma estrutura" (MELLA, 1997), corporizando uma unidade durável constituída por elementos. Segundo Mella, as principais caraterísticas constitutivas dos sistemas são:

1. o sistema deve ser observável como uma unidade durável (visão sintética) com significado próprio (macro) a fim de, na conjugação dos seus elementos, parecer novo e emergente; 
2. todos os elementos do sistema (macro) compõem uma estrutura estruturante e estruturada, na qual cada elemento contribui para a existência da estrutura mais subordinada ao próprio estado da existência do sistema (visão analítica);

3. há uma correlação permanente (feedback micro-macro) entre a unidade (totalidade) e os elementos (partes): por um lado, o sistema torna-se uma unidade na multiplicidade dos seus componentes; e, por outro, as partes perdem, no sistema, a sua individualidade, tornando-se igualmente essenciais na formação da unidade" (MELLA, 1997 apud SILVA, 2006, p. 30; SILVA e RIBEIRO, 2002, p. 96).

Uma conceção holística que se aplica a uma gama diversa de objetos cognoscíveis, máquinas, organizações, seres vivos, etc. e que se pretende irredutível a tendências ou escolas, apesar da proximidade existente entre o pensamento sistémico e uma corrente como o estruturalismo (PINTO, 2015, p. 39-111), dada a sua estreita ligação com o estudo das Instituições e das Organizações, e que aqui se reflete na confrontação por Mella dos conceitos de Estrutura e Sistema, revisitado por Silva que, na sinopse que elabora, salienta nessa confrontação o par estrutura e comportamentos e o par conceção analítica e conceção sintética, referindo que:

[...] para definirmos operatoriamente o sistema, devamos entender a estrutura como um complexo unitário formado por uma pluralidade de elementos relacionados entre si e de tal forma que: (a) apresente características próprias; (b) o estado de cada elemento dependa pelo menos de um outro e acabe condicionado pela estrutura toda; (c) esta, se assumir ou modificar o próprio "estado", afecta os seus elementos, assumindo cada um deles um dado estado ou sofrendo uma modificação de estado; e (d) todos os elementos são necessários para formar aquela estrutura (MELLA, 1997: 25). Infere-se, assim, que toda a estrutura é, simultaneamente, estruturada (o seu estado deriva dos elementos integrantes) e estruturante (o seu estado condiciona o dos elementos). E importa notar que estrutura e sistema sem coincidirem correspondem a uma concepção analítica e a uma síntese na observação dos elementos interrelacionados.

Assim, um sistema pode ser definido enquanto estrutura (concepção analítica) observada como uma unidade duravelmente caracterizada pelo próprio estado e com significado autónomo (concepção sintética). [...] (MELLA, 1997, p. 26) (SILVA, 2006, p. 30; SILVA e RIBEIRO, 2002, p. 95).

Estrutura e comportamentos configurados na dinâmica e consequente complexificação da própria Estrutura, estão intimamente relacionados e poderão estar na base de metamorfoses envolvendo os tipos sistémicos identificados por Mella (o Macrossistema, o Supersistema, o Sistema e o Sistema parcial ou Subsistema), sendo a unidade em análise passível de perspetivação ora pela vertente Estrutura, ora pela vertente Comportamento, e tipificada em função de cada uma delas. 
Considerando que o Sistema se torna uma unidade na multiplicidade dos seus componentes, e se estes, no sistema, perdem a sua individualidade "tornando-se igualmente essenciais na formação da unidade", há, também, que considerar a dinâmica inerente aos Elementos/Componentes, partes do Sistema que emergem e evoluem no contexto do todo unitário de que fazem parte e que, perdendo a sua "individualidade", tal não significa diluição, proporcionando, ao nível da possibilidade de perspetivação por Componente, a metamorfose do Sistema unitário de que fazem parte em Supersistema (o Sistema é constituído por sistemas específicos - partes) inserindo-se aqui elementos/componentes diversas como: a institucional/organizacional, a informacional, a tecnológica (as três que relevaremos), entre outras.

A proposta de classificação de sistemas de Mella (1997) abarca duas grandes classes de sistemas - a dos "Não Organizados ou Combinatórios" e a dos "Organizados ou Operatórios" evidenciando, respetivamente, a conceção sintética e a conceção analítica da definição de sistema.

No primeiro caso, Sistemas "Não Organizados ou Combinatórios", incluem-se as macro unidades, unidade ampla que, através de interações e feedback entre as partes constituintes, é formada pela reunião de elementos semelhantes (micro-comportamentos) que, por princípio, não mantêm uma relação organizada entre si. O Sistema constitui, assim, uma estrutura gerada por elementos análogos, através dos quais não se reconhecem relações organizativas.

No segundo caso, Sistemas "Organizados ou Operatórios", encontram-se as situações em que há uma organização estrutural, na qual uma unidade (o todo) é constituída por elementos (as partes), independente das suas especialidades, através de relações estáveis no âmbito das suas funções, é o caso das estruturas formada por órgãos (por exemplo organismos naturais ou artificiais como o corpo humano ou um automóvel), em que cada parte que integra o todo tem as suas funções específicas (corporizando subsistemas especializados), resultando o conjunto sustentado em relações organizadas num determinado produto.

$\mathrm{Na}$ investigação realizada e no que respeita aos elementos/componentes, ao Sistema Social, que se especifica no "Sistema Institucional" (SIns) corporizado na Universidade, ter-se-á que acrescer o "Sistema de Informação" (SI), conceito fundamental em $\mathrm{Cl}$, e vincar a sua diferenciação face ao "Sistema Tecnológico de Informação" (STI), do qual é, todavia, indissociável o mesmo acontecendo face ao SIns, envolvendo conceitos relacionados como o de "Organicidade", que aponta para estrutura produtora/acumuladora, bem como os de "Meio ambiente", "Contexto" e "Situação", que apontam para o serviço/uso/comportamento e se espelham no conceito de "Funcionalidade", aos quais se juntará o de "Memória":

"Dotado de movimento e de finalidade, o sistema geral possui [...] memória e organização, sendo esta a propriedade do sistema que permite desenvolver sucessões de comportamentos não exclusivamente aleatórios. A organização pressupõe a existência de memória e compreende uma parte fixa (hardware) ou estrutura e uma parte variável (software) constituída pelo programa em uso na estrutura, isto é, um programa operativo, enquanto na parte fixa deparamos com o programa genético-regulador." (SILVA e RIBEIRO, 2002, p. 101) 
O SI é, pois:

\begin{abstract}
“[...] constituído pelos diferentes tipos de informação registada ou não externamente ao sujeito (o que cada pessoa possui em sua memória é informação do sistema), não importa qual o suporte (material e tecnológico), de acordo com uma estrutura (entidade produtora/receptora) prolongada pela acção na linha do tempo. A estrutura de um S.I. é um aspecto complexo porque ela é paradoxalmente autónoma e indissolúvel da informação propriamente dita: o sujeito de acção (seja pessoa ou instituição) que produz e recebe fluxo informacional é distinto deste, mas é essencial para que este exista" (SILVA, 2006, p. 162-163)
\end{abstract}

Como exposto por Silva, um Arquivo ou uma Biblioteca, enquanto serviços, podem fazer parte de um Sistema, ou, enquanto instituições, podem constituir um Sistema. Porém, não se podem confundir com o SI o qual compreenderá toda a informação produzida/recebida e acumulada na Organização/Instituição, independentemente da existência de um serviço Arquivo, Biblioteca, Centro de Documentação ou Museu - que a processe, armazene e difunda.

Neste sentido, o STI não detém o exclusivo da condição sistémica, constituindo, de facto, uma parcela sendo assumido na perspetiva $\mathrm{Cl}$ como a plataforma tecnológica - meio físico e lógico - que sustenta a produção, processamento, circulação, armazenamento, transmissão e acesso à informação que constitui o SI propriamente dito (SILVA, 2006, p.163).

Delimitam-se, desta forma, três componentes sistémicos essenciais: o do Sistema Institucional/Organizacional, o do Sistema de Informação (ou SIO que resulta da materialização do fenómeno infocomunicacional social e humano) e o do Sistema Tecnológico de Informação (que suporta a ação e, consequentemente, o SIO, abarca os Ssl e, nestes, as TI).

\title{
3.10 binómio teoria-modelo
}

Para a abordagem modelar destes elementos/componentes socorremo-nos do "instrumento" teórico-metodológico orientador corporizado no Modelo Sistémico e Integral de Informação Ativa e Permanente (SIAP), cujos pressupostos epistemológicos e teóricos formulamos com Armando Malheiro da Silva (PINTO e SILVA, 2005), tendo em conta os traços fundamentadores do novo paradigma científico, pós-custodial, dinâmico e informacional em desenvolvimento para a área da Informação (SILVA [et al.], 1999; SILVA e RIBEIRO, 2002), e que Silva tipificou como sistémico-informacional.

Ao nível do conceito e papel a desempenhar pelos modelos, hoje são sobejamente conhecidas as chamadas frameworks que pretendem de uma forma cientificamente sustentada e marcadamente interdisciplinar, conciliar "arquiteturas" e os modelos de atuação/gestão ao nível "corporativo" e de "sistemas" (por exemplo, as de ZACHMAN) mas, de facto, o termo modelo acompanha o desenvolvimento científico desde meados do século XIX, suscitando debates e reflexões epistemológicas e verificando-se a tendência para a sua vinculação a uma teoria, o binómio teoria-modelo de Pierre Delattre (SILVA, 2010), e a necessidade de modelação, quer ao nível da produção de conhecimento cientifico quer ao nível aplicado e de operacionalização.

\footnotetext{
${ }^{7}$ Com as versões de: 1984, 1987, 1992, 1993, 1999, 2001, 2003, 2004, 2011.
} 
Armando Malheiro da Silva analisa o conceito de modelo (SILVA, 2010) ${ }^{8}$ e reconhece que da Ciência em geral até às Ciências da Informação e Comunicação (CCl) ainda há um trajeto a fazer no âmbito da determinação do papel do modelo e da modelização na dinâmica da investigação científica, concluindo que:

Independentemente da escala e do enfoque de aplicação, qualquer modelo, físico ou conceptual, é a formalização matemática de um fenómeno real e é, ainda, a antecipação racional tendente a produzir um efeito no futuro. (SILVA, 2010, p. 2)

No campo da $\mathrm{Cl}$, Silva destaca a relevância que ganha a afinidade com o modelo sociológico ou o modelo comportamental social, não deixando de apontar na área da Gl os contributos para a objetivação e delimitação do uso do termo e para a sua aplicação em $\mathrm{Cl}$, nomeadamente os primeiros passos dados com a formulação do Modelo Sistémico de Informação Ativa e Permanente - SIAP - (PINTO e SILVA, 2005) que emerge como um modelo teórico com vista à operacionalização e se desenvolve ao longo da última década, em função das necessidades sentidas e resultados obtidos aquando da conceção e execução de estudos de caso/projetos ${ }^{9}$ no âmbito da Gl em contexto organizacional:

[em Gl] o modelo tende a ser mais lógico ou conceptual que matemático e visa resolver um emaranhado de problemas (modelo total), ou apenas um problema específico (modelo parcial). Para cumprir o desiderato mais geral, e até o mais específico, há vantagem em vincular o modelo a uma teoria, ou seja, o modelo torna-se uma operacionalização teórica, através de uma intervenção prática em busca de resultados concretos (ou da melhoria de indicadores operativos, como eficácia, eficiência, rapidez, usabilidade, etc.) (SILVA, 2010).

[o SIAP] inspirado na teoria dos sistemas (Ludwig von Bertalanfy, Niklas Luhmann, Bruno Lussato...) e composto por vários módulos, que correspondem a duas fases distintas: a do diagnóstico/análise e a da explicação. Aquela é essencialmente descritiva e "radiográfica", na medida em que põe em relevo características e problemas vários, associados a um caso concreto em estudo; e esta é interventiva ao apresentar soluções de curto, médio e longo prazo com um plano de optimização de resultados positivos bem definido" (SILVA, 2010) ${ }^{10}$.

\footnotetext{
${ }^{8}$ Nas tipologias identifica as seguintes: Modelo em Física Teórica, Modelo Meteorológico e Climático, Modelo em Engenharia, Modelo de Decisão em Gestão Ambiental, Modelo Econômico, Modelo Político (NOUVEL, 2002: 29-185 apud SILVA, 2010).

${ }^{9}$ Contribuíram para a sua formulação projetos como: a pioneira análise e estudo orgânico-funcional relativo à Universidade do Porto (RIBEIRO e FERNANDES, 2001); o Sistema de Informação Municipal de Vila do Conde (PINTO, 2001, 2003, 2005, 2007; PINTO e SILVA, 2005) e o Sistema de Informação Municipal Ativa de Indaiatuba - SIMAI (MASSON, SILVA, 2001; MASSON, 2004) e o projeto SI@P-FLUP (2005-2007) desenvolvido na FLUP e que esteve na base da reconfiguração orgânica do Serviço de Documentação da FLUP para Direção de Serviços de Documentação e Sistemas de Informação, agregando Biblioteca Central, Bibliotecas Departamentais, Serviço de Gestão de Informação Ativa e Permanante (que engloba o setor de Gestão de Processos, o setor de Gestão do Sistema de Informação SIGARRA e o Arquivo Central) e Serviços de Informática e Infraestruturas Tecnológicas.

${ }^{10}$ Sublinhado nosso.
} 
Silva coloca o Modelo SIAP $^{11}$ na categoria dos modelos sistémico-informacionais, acrescendo mais três modelos desenvolvidos em $\mathrm{Cl}$ na última década: o Modelo Semântico para Estruturar Informação (MSEI) ${ }^{12}$, o Modelo de Serviços de Informação ${ }^{13}$ e o elit.pt ${ }^{14}$, que se situa no âmbito da Literacia Informacional:

Em contraponto a estes modelos e em particular ao de Carol Khulthau, "é possível exibir quatro [...]. São modelos inscritos na $\mathrm{Cl}$ trans e interdisciplinar, evidenciando, como traço matricial, a precedência obrigatória de uma teoria fundamentadora do modelo. O cariz emergente do paradigma pós-custodial, informacional e científico e da $\mathrm{Cl}$, que lhe é inerente, explica que o leque de modelos seja ainda restrito e escasso, mas a tendência natural é a multiplicação crescente. (SILVA, 2010).

$\mathrm{Na}$ investigação realizada retivemos, sobretudo, a pista de investigação que suscita quando aponta os debates interessantes que se abrem, e, sobretudo, "[...] se o genuíno "espírito" do SIAP comporta incursões pelo plano estritamente de gestão e de (re)configuração organizacional" (SILVA, 2010, p. 3).

O modelo SIAP surge, assim, como alternativa à corrente que emergiu nos anos 80/90, do século XX, na qual se verifica a aproximação da Documentação, herdeira de Otlet, e da Gestão Documental, herdeira dos Records Management, às metodologias, práticas e aplicações emergentes em áreas como a Informática, a Gestão e as Ciências da Administração e das Organizações (PINTO e SILVA, 2005).

Inspirado na Teoria Sistémica, este modelo tem a $\mathrm{Cl}^{15}$ como base delimitadora, resultando os fundamentos teóricos em que se sustenta de uma primeira formulação

11 "O modelo tem sido e está a ser aplicado em vários casos por arquivistas/cientistas da informação: "Arquivo da Casa de Mateus (Vila Real)", "Arquivo da Família do Conde da Barca" (existente no Arquivo Distrital de Braga, Universidade do Minho), "Arquivo da Casa do Avelar" (existente no Arquivo Distrital de Braga, Universidade do Minho), Arquivo do Paço de Calheiros (Ponte de Lima), Sistema Pessoal e Familiar de Mário Cesariny (existente na Fundação Cupertino de Miranda, Vila Nova de Famalicão) etc." (SILVA, 2010, p. 39).

12“Májory Miranda, ao tratar a problemática do acesso à informação no paradigma pós-custodial, chegou à elaboração de um modelo aplicado diretamente à findability. Trata-se do MSEI - Modelo Semântico para Estruturar Informação e que se compõe de um enunciado principal, desenvolvido em três eixos: informação, intencionalidade e sistema de informação. O seu objetivo é orientar o relacionamento em SRI - Sistemas de Recuperação da Informação e explorar a participação do utilizador. Aspeto saliente desta proposta é a ênfase posta na fundamentação teórica do modelo, assegurada pela teoria da intencionalidade de recorte fenomenológico." (SILVA, 2010, p. 40-41).

13 "[...] como corolário lógico da trajetória seguida, a apresentação de um modelo claramente baseado na teoria dos sistemas. No entanto, destaca-se uma particularidade interessante, pois está voltado mais para o ajustamento [d]o modelo sistémico ou do SIAP e não tanto ao tratamento organizativo e descritivo da totalidade da informação produzida/recebida e acumulada, numa entidade hospitalar, embora isto esteja, naturalmente, implicado no projeto em foco, mas sobretudo à estrutura do Departamento da Informação. O modelo de Serviços de Informação é integrado em novos modelos de gestão hospitalar que refletem a organização." (SILVA, 2010, p. 41).

${ }^{14}$ Para o qual também contribuímos: "Ao longo do projecto, a equipa, que se manteve ligada e operacional, foi constituída por quatro docentes da Faculdade de Letras da Universidade do Porto e investigadores do Centro de Estudos em Tecnologias e Ciências da Comunicação - Armando Malheiro da Silva, José Manuel Pereira Azevedo, Maria Fernanda Silva Martins e Maria Manuela Gomes de Azevedo Pinto - e uma consultora da Universidade de A Coruña, campus de Ferrol, Galiza, Espanha, Viviana Fernandez Marcial" (SILVA, 2010, p. 42).

${ }^{15} \mathrm{Na}$ perspetiva proposta por SILVA e RIBEIRO (2002). 
condensada em Arquivística : teoria e prática de uma ciência da Informação (SILVA [et al.], 1999), detalhada e desenvolvida no ensaio epistemológico Das "ciências" documentais à ciência da informação: ensaio epistemológico para um novo modelo curricular (SILVA e RIBEIRO, 2002), bem como de três projetos de aplicação, diferentes mas complementares entre si: a análise relativa à Universidade do Porto: estudo orgânico-funcional (RIBEIRO e FERNANDES, 2001); o Sistema de Informação Municipal de Vila do Conde (PINTO, 2001a, 2001b, 2003, 2004, 2005b, 2007a, 2007b; PINTO e SILVA, 2005) e o Sistema de Informação Municipal Ativa de Indaiatuba SIMAI (MASSON, SILVA, 2001; MASSON, 2004), consolidados com a experiência no projeto SI@PFLUP (2005-2007) $)^{16}$.

Como enunciado em 2005, o Modelo SIAP é constituído por quatro Módulos e apresenta cinco caraterísticas principais (PINTO e SILVA, 2005) ${ }^{17}$ :

1. a noção estática e analógica de documento ${ }^{18}$ é subordinada à noção operatória de INFORMAÇÃO, definida como "[...] o conjunto estruturado de representações mentais e emocionais (signos) e modeladas com/pela interacção social, passíveis de serem registadas num qualquer suporte material (papel, filme, banda magnética, disco compacto, etc.) e, portanto, comunicadas de forma assíncrona e multidireccionada" (SILVA, 2006 ,p. 150). Clarificando:

- a delimitação da distinção entre a UNIDADE DE SENTIDO e a unidade física;

- a reflexão dirigida aos emergentes Doc-Media e Media-Doc, bem como à complexificação do processo infocomunicacional - o mesmo suporte "[...] onde sou capaz de memorizar informação, serve tanto para a transmitir, sem que tenha de a inscrever ou gravar, como para a transmitir e inscrever, ou gravar em simultâneo" (SILVA, 2012);

- a complexificação dos perfis dos atores desse processo: produtor, utilizador/consumidor e PROSSUMIDOR de informação;

2. o MÉTODO QUADRIPOLAR da Cl é a matriz fundamentadora do SI(integral)AP;

3. a adoção da TEORIA SISTÉMICA e da noção de SISTEMA $^{19}$, em linha com o pensamento de Piero Mella (1997), envolvendo a sua aplicação filosófico-

16 Projeto coordenado por Fernanda Ribeiro, no qual participou a doutoranda, que decorreu na Faculdade de Letras da Universidade do Porto entre 2005-2007 e de cuja equipa também faziam parte: João Leite, Letícia Silva (até janeiro de 2007), Margarida Santos, Susana Oliveira e Vítor Pereira.

${ }^{17}$ Especificação atualizada da formulação constante em: PINTO e SILVA (2005).

${ }^{18}$ Entenda-se: conteúdos + qualquer suporte físico [a pedra, a madeira...], técnico [papiro, pergaminho, papel...] ou tecnológico [tipografia, litografia, xilografia, zincogravura, fotografia, fita magnética, registo eletrónico, mecanográfico, digital...].

${ }^{19}$ Recupere-se parte da análise apresentada: "[...] um sistema pode ser definido enquanto estrutura (concepção analítica) observada como uma unidade duravelmente caracterizada pelo próprio estado e com significado autónomo (concepção sintética). Não sendo uma estrutura, o sistema pressupõe, possui ou integra uma estrutura duradoura com um fluxo de estados no tempo. Um sistema não existe na realidade, mas é definido como tal por qualquer observador que dê significado aos estados (ou 
sociológica ao fenómeno e processo infocomunicacional as seguintes implicações diretas:

- a produção (génese do fluxo), o fluxo e o uso de Informação é indissociável da complexidade humana e social (Sistema Institucional e Sistema de Informação);

- pensar e estudar a Informação como Sistema implica superar divisões ou separações convencionais ainda vigentes (por suporte, por temática ou por categoria de serviço gestor - Arquivo, Biblioteca, Centro de Documentação, Museu ...);

- os Sistemas [Tecnológicos] de Informação (STI) não detêm o exclusivo da condição sistémica, constituindo, apenas, uma parte/componente dentro da noção de Sistema (na aceção exposta e que articula SInst, SI e STI);

- e, decorrente da premissa anterior, a perspetiva epistemológica que configura a $\mathrm{Cl}$ como um campo transdisciplinar que congrega a Arquivística, a Biblioteconomia, a Documentação, a Organização e Métodos e as Tecnologias de Informação, configurando com as Ciências da Comunicação uma interdisciplina (CCI), no seio das Ciências Sociais (CS) e em interação com interciências como os Sistemas [Tecnológicos] de Informação e as Ciências Cognitivas;

4. um SISTEMA DE INFORMAÇÃO integral (SI), fruto da relação transdisciplinar, implica:

- uma revalorização de noções habituais, mas que precisam de ser (re)significadas e operacionalizadas: AMBIENTE, CONTEXTO, SITUAÇÃO, ORGANICIDADE, pessoal e/ou institucional ou organizacional, e necessidade de procura/aquisição, de organização, de armazenamento, de preservação, de recuperação, de difusão, de reprodução e de transformação ${ }^{20}$ (foco de estudo/pesquisa e dos modelos aplicacionais de comportamento informacional, antigos estudos de utilizadores ou utilizadores/clientes de informação/documentos):

o [meio] AMBIENTE - significa a realidade política, económica, social e cultural que condiciona e envolve os contextos e situações

situações) assumidos por uma estrutura (MELLA, 1997: 26 apud DELTCI) Cf. DELTCl - Dicionário Electrónico de Terminologia em Ciência da Informação. Verbete Sistema. [Em linha]. [Consult. 30 ago. 2017]. Disponível em www: <url:https://paginas.fe.up.pt/ Ici/index.php/1758.

${ }^{20}$ Foco de estudo/pesquisa e dos modelos aplicacionais de comportamento informacional, antigos estudos de utilizadores ou usuários/clientes de informação/documentos. 
comportamentais relativas ao fluxo e ao uso/reprodução de informação (DELTCI, 2011 e SILVA, 2006).

- CONTEXTO - é um conceito operatório oportuno, a par de meio ambiente, com óbvias vantagens no seu uso estrito no âmbito das atitudes humanas e sociais emergentes do fenómeno infocomunicacional. Assim, define-se como uma unidade agregadora de elementos materiais (um edifício, um ou mais aposentos quaisquer que constitui cenário para a ação infocomunicacional), tecnológicos (mobiliário, material de escritório, computadores com ou sem ligação à Internet, etc.) e simbólicos (o estatuto e os papéis desempenhados pelas pessoas ou atores sociais) que envolvem o(s) sujeito(s) de ação infocomunicacional através de momentos circunstanciais delimitados cronologicamente (situação). Engloba dois tipos essenciais: ORGÂNICO e EFÉMERO ${ }^{21}$. O contexto orgânico pode ainda ser INSTITUCIONAL/ORGANIZACIONAL (em que a unidade agregadora é determinada estruturalmente por uma instituição ou organização pública ou privada, mas com aparelho político-administrativo) e INFORMAL (em que a unidade agregadora é determinada estruturalmente por entidades individuais e coletivas, sem ou com reduzido aparato burocrático e de génese e extinção rápidas) (DELTCI, 2011; SILVA, 2006);

- SITUAÇÃO - termo usado em comportamento informacional, identifica o estado circunstancial, temporário, de duração mais ou menos reduzida e contínua, que dá historicidade à ação informacional propriamente dita. Definida, assim, leva vantagem sobre o sentido ambíguo e demasiado abrangente usado na "teoria das situações" (DEVLIN, 2000, p. 60). Quando um contexto é demasiado efémero confunde-se com situação, mas, em geral, cada contexto orgânico compreende um número ilimitado de situações e é dentro destas que se desenrolam as atitudes e as

\footnotetext{
21 "O contexto efémero possui uma variedade de graus que vão do mais acidental e volátil, como é o caso de um grupo de pessoas conhecidas que se encontram na rua a conversar (emitir e receber informação), o caso dos comícios, das manifestações espontâneas e organizadas, etc., podendo confundir-se com situação, até ao mais perene e regulado, como é o caso das tertúlias de amigos que se reúnem periodicamente. Este tipo concreto de contexto efémero pode converter-se em contexto orgânico informal. Quando os contextos se cruzam, sobrepõem ou coexistem estamos perante uma relação contextual de complexidade variável". DELTCI - Dicionário Electrónico de Terminologia em Ciência da Informação. Verbete Contexto. [Em linha]. [Consult. 30 ago. 2017]. Disponível em www: <url:https://paginas.fe.up.pt/ Ici/index.php/1701.
} 
necessidades comportamentais dos sujeitos face à informação (DELTCl, 2011; SILVA, 2006);

- um enfoque especial na ORGANICIDADE:

- constitui a capacidade de toda e qualquer Organização (baseada ou mediada por estrutura administrativa e funcional ou orgânico-funcional) agir em todos e diversos níveis para atingir, concretizar e rentabilizar objetivos centrais/genéricos e específicos ou ligados à natureza do "segmento" público-privado, político-social e socioeconómico da Organização;

- conceito que chega à $\mathrm{Cl}$ pela via da Arquivística (a partir da década de oitenta do século $\mathrm{XX}$ ) onde ocorre o equívoco de confundir orgânico com administrativo, não sendo, de facto, a organicidade propriedade exclusiva de entidades dotadas de aparelho jurídico-administrativo ou burocrático;

o relaciona-se com ação consciente (humana e social), seja rotineira ou criativa, jurídico-administrativa ou artística, científica ou literária, geradora de informação numa situação, dentro de um contexto orgânico (institucional e informal) e condicionada por um determinado meio ambiente, evidencia organicidade, cuja variação e "textura" é avaliável;

- será tanto maior quanto mais clara e profunda for a articulação entre o sujeito da ação (pessoal ou institucional) com sua estrutura própria (conceito lato: vai do corpo humano ao dispositivo organizacional de uma qualquer entidade instalada em imóveis e com equipamento vário) e os objetivos mobilizadores que se propõe naturalmente atingir. Entra aqui o esquema cibernético da retroação porquanto a fixação e a obtenção de objetivos (sendo, então, fixados outros novos) rege diretamente a formação e a renovação da MEMÓRIA ORGÂNICA essencial à ação (DELTCI, 2001; SILVA, 2006);

- um SISTEMA DE INFORMAÇÃO (integral) ATIVO E PERMANENTE (SIAP) 22:

- traz ao pragmatismo, de pendor técnico e tecnológico, da GESTÃO DA INFORMAÇÃO o capital simbólico da MEMÓRIA ORGANIZACIONAL ou INSTITUCIONAL, sem o qual não é possível lançar ou projetar para os modelos

\footnotetext{
${ }^{22}$ Cf. (PINTO e SILVA, 2005, p. 7-8).
} 
(incluindo os produzidos no âmbito das diversas componentes da Gestão e das Organizações) uma matriz científica e retrospetiva (contextualizadora);

- exige a adoção de uma operação metodológica inscrita no MÉTODO QUADRIPOLAR da Cl proposta por Silva e Ribeiro (2002, p. 79-121).

O conjunto de caraterísticas apresentado é associado a um "perfil esquemático teórico-prático e agregador de técnicas metodológicas provenientes da referida tradição documentalista e arquivística, dos Sistemas [Tecnológicos] de Informação, da Gestão e da Sociologia das Organizações" (PINTO e SILVA, 2005) e que também conta com o contributo da aprendizagem extraída da experiência no terreno e do percurso investigativo que realizamos, sendo evidente que a Gl se insere e envolve todo o Sistema Institucional/Organizacional, componente institucional/organizacional e os seus colaboradores, constituindo a sua identidade/self/cultura o indicador do carácter único e particular de cada uma delas que, assim, se projeta no Sistema de Informação (integral) Ativa e Permanente da Organização ${ }^{23}$ (Figura 2).

${ }^{23}$ Cf. Em 2005, e na sequência dos projetos desenvolvidos eram evidentes a falta de planificação do Sistema de Informação e a procura de soluções "avulsas" para a resolução de problemas pontuais/setoriais de curto/médio prazo, sendo uma realidade no universo empresarial que urgia alterar profundamente. A má prática prevalecia em muitos casos: não se identificavam as necessidades de informação, o uso da informação não era direcionado à estratégia da Organização, multiplicava-se a informação redundante, não existia avaliação da informação, não existia integração, a mesma informação encontrava-se dispersa por diversos suportes, não se aplicava a normalização, aumentavamse desnecessariamente os custos de manutenção e de transferência de suporte, perdia-se produtividade, não se cumpriam as políticas e os objetivos da Organização, corria-se o risco de incumprimento dos próprios imperativos legais. 
Figura 2 - Representação do SIAP (PINTO e SILVA, 2005; PINTO, 2003²4)

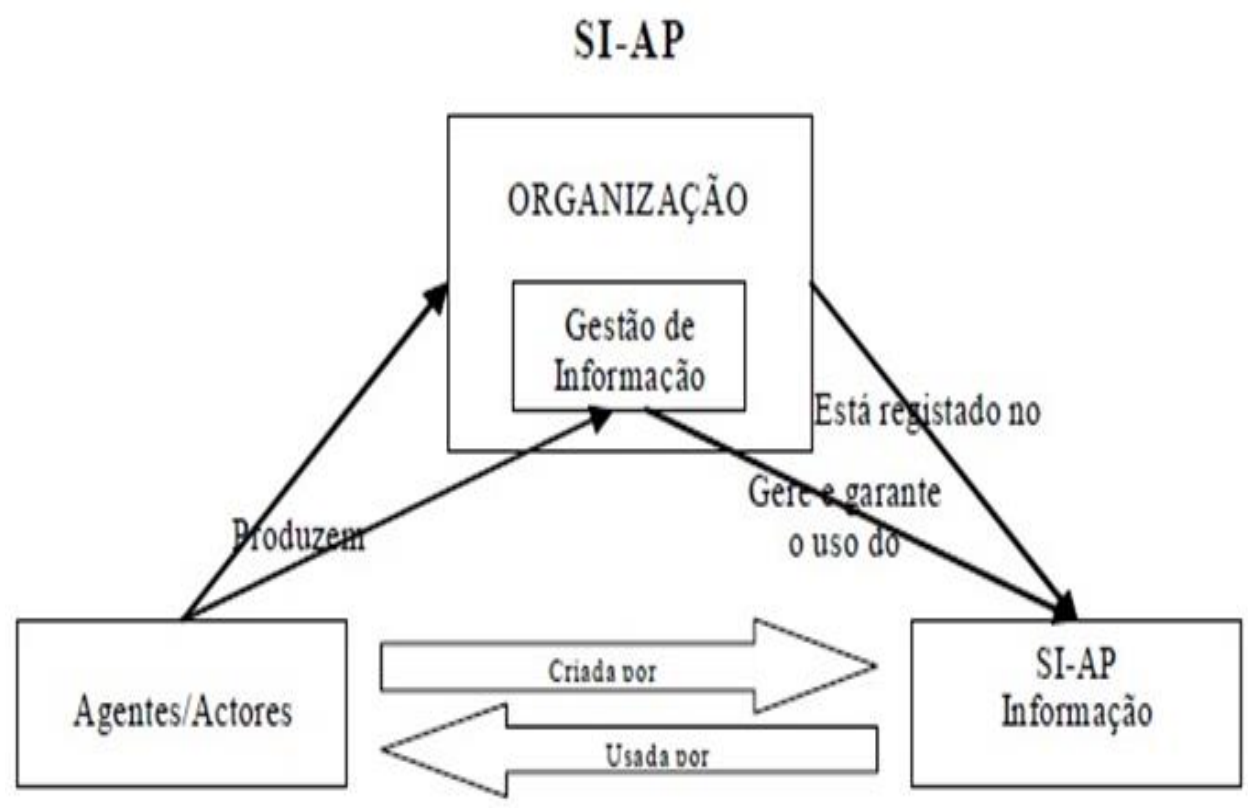

A representação gráfica do modelo SIAP (PINTO e SILVA, 2005; PINTO, 2003, 2004, 2005b, 2007) teve na sua origem a análise de modelos quer da área dos Records Management (RM), quer dos Archives Management (AM), constituindo uma reinterpretação da representação de Recordkeeping e de Business Context inserta no relatório "Conceptual and Relationship models : Records in Business and Socio-legal Contexts" do projeto liderado por Sue McKemmish e outros autores ${ }^{25}$, entre 1998 e 1999.

Uma versão simplificada e alinhada com os pressupostos teóricos de que se partiu para o desenvolvimento do Modelo SIAP (Sistema de Informação Ativa e Permanente), isto é, com o foco na $\mathrm{Gl}$, com o pensamento sistémico como ferramenta interpretativa, assumindo a informação como objeto e com vista à estruturação do SIAP no contexto institucional/organizacional.

\subsection{Um caminho para um Modelo de Gestão de Informação}

${ }^{24}$ A versão 0 foi desenvolvida em 2003 com base em MCKEMMISH, Sue; WARD, Nigel Describing Records in Context : the Recordkeeping Metadata Schema (RKMS). [Em linha]. [Consult. 26 Jun. 2007]. Disponível em www:url:http://www.archiefschool.nl/docs/rkmsdesc.pdf p. 14.

${ }^{25}$ Produzido no âmbito do projeto de investigação desenvolvido na Monash University entre 1998-1999 "Recordkeeping Metadata Standards for Managing and Accessing Information Resources in Networked Environments Over Time for Government, Commerce, Social and Cultural Purposes" liderado por Sue McKemmish, Ann Pedersen e $\quad$ Steve Stuckey. http://www.sims.monash.edu.au/research/rcrg/research/spirt/reports.html, também publicado em "Describing Records in Context: the Recordkeeping Metadata Schema (RKMS)", p. 14 http://www.archiefschool.nl/docs/rkmsdesc.pdf e, posteriormente, adotado e incluído na norma ISO 23081-1:2006 Information and documentation. Records management processes. Metadata for records. Part 1: Principles, p. 11. 
Foi neste enquadramento que desenvolvemos e orientámos diferentes estudos em torno da GI (PEREIRA, 2013; SOUSA, P. 2013; GAVINA, 2014; OLIVEIRA, H. 2014; MAGALHÃES, 2014) e que mais recentemente conduziram à enunciação das bases do Sistema de Gestão de Informação Ativa e Permanente (SGIAP) (GAVINA, 2014 e GAVINA e PINTO, 2017) que operacionaliza o modelo teórico através de um Sistema de Gestão normativamente alinhado:

\begin{abstract}
Gerir para Preservar e Aceder expressa claramente uma nova perspetiva que abarca, simultaneamente, modelos teóricos e modelos de operacionalização concebidos e implementados no âmbito de uma $\mathrm{Gl}$ que integra a Preservação da informação como sua variável e se direciona à construção de um SIAP, isto é, de um Sistema de Informação Ativa e Permanente no seio de uma qualquer organização ou instituição que se quer fortemente comprometida com a área da $\mathrm{Gl}$, assumindo-a e situando-a entre os seus Sistemas de Gestão, nomeadamente com a implementação de um Sistema de Gestão de Informação [Ativa e Permanente] (SGIAP) (PINTO, 2015).
\end{abstract}

Para a configuração do SGIAP (Figura 3) partiu-se da representação do modelo SIAP para uma versão de operacionalização que incorporasse as mais recentes propostas para a estruturação já não de um EDMS (Electronic Documents Management System), ou de um ERMS (Electronic Records Management System), mas do que na mais recente produção normativa é designado por Management System for Records (MSR), isto é, um "Sistema de Gestão de Informação" no âmbito do modelo dos chamados "Sistemas de Gestão ISO", onde se situam, entre outros, os muito difundidos Sistemas de Gestão da Qualidade (SGQ) e, como estes, passível de certificação.

Nesta abordagem com vista à produção de um Documento de Requisitos para o desenvolvimento de uma solução de software compatível com o MoReq2010 e que pudesse funcionar como componente tecnológico do SGIAP a construir na Organização, Gavina valida os pressupostos teóricos do modelo SIAP e incorpora no âmbito da operacionalização:

- ao nível organizacional e de gestão estratégica: a ISO 30300 e a ISO 30301 (BUSTELO, 2012; JIMENEZ, 2012), encontrando-se em preparação a ISO 30302 (Guide of implementation a MSR);

- ao nível tecnológico: o modelo de especificação de requisitos orientado a serviços do MoReq2010, cruzado com a ISO 16175 (Parte 1, 2, 3) (ELLIS, 2012);

- ao nível das operações: a ISO $15489^{26}$, alinhada com os módulos do modelo teórico sistémico-informacional SIAP.

\footnotetext{
${ }^{26}$ A ISO 15489 - International Standard for Records Management, teve na sua origem a AS 4390 e esta resulta da metodologia DIRKS, equivalente ao DoD 5015.2-STD (US).
} 
Figura 3 - Configuração global do SGIAP

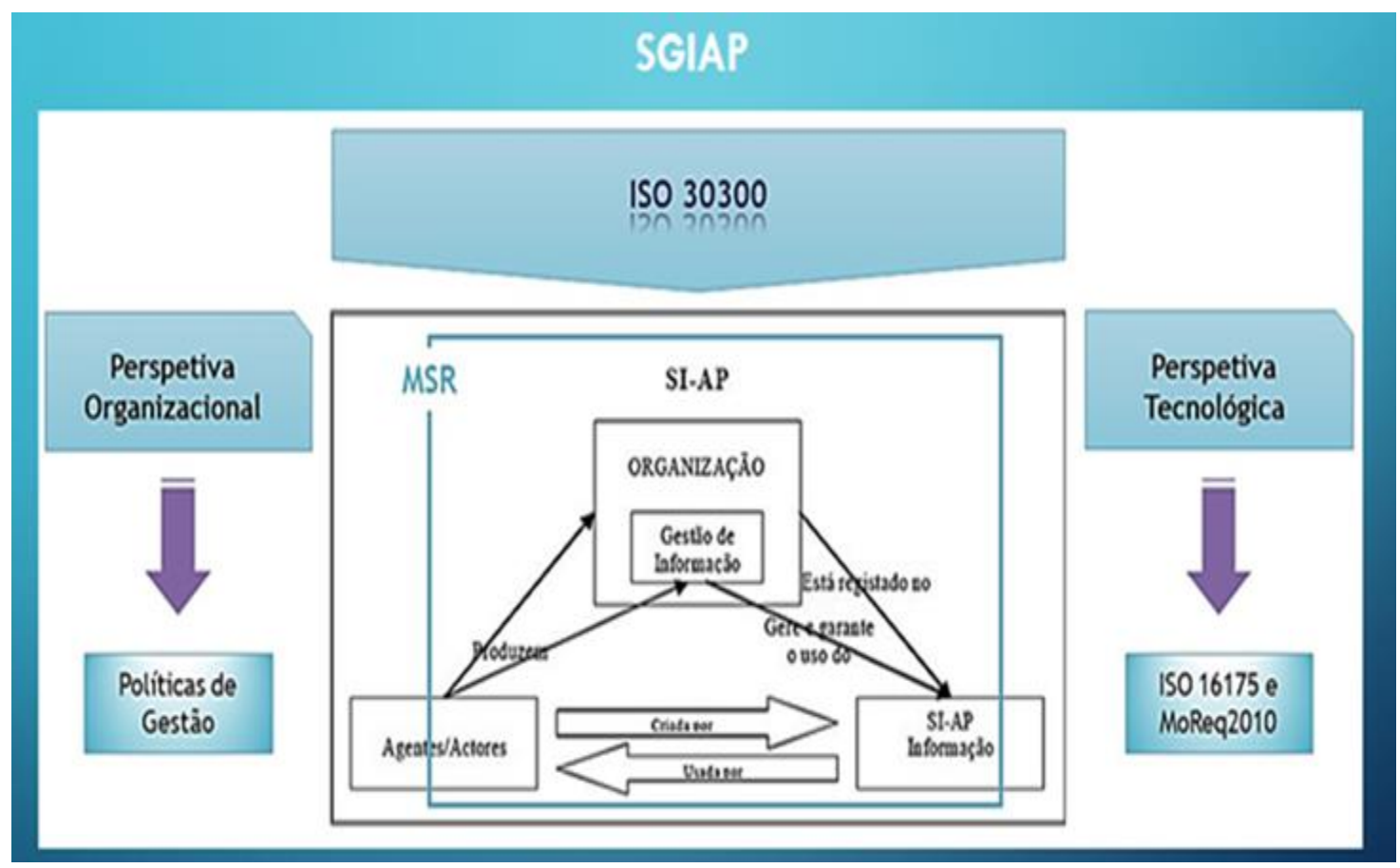

Fonte: GAVINA, 2014 adapt. de PINTO e SILVA, 2005.

Dessa análise resultou um esboço de proposta de configuração global do SGIAP na base do qual está o modelo teórico SIAP que sustenta a GI no contexto organizacional, sendo acrescida para a sua operacionalização a perspetiva Organizacional, refletida desde logo nas Politicas e Estratégias de Gestão da Organização/Instituição com as quais se procura alinhar a GI, e a perspetiva Tecnológica, que implementa as mais recentes orientações ao nível dos requisitos de desenvolvimento de software para a estruturação de um Sistema de Gestão de Informação e para a Gl em ambientes de "escritório eletrónico".

Em termos gerais, partindo do Modelo Teórico SIAP, foca-se o fenómeno infocomunicacional que emerge como um processo/fluxo no qual a produção e uso da informação constituem processos humanos (surgem na mente) e processos sociais (surgem na e para a interação/comunicação) desenvolvendo-se a estruturação do SIAP, que, em rigor, se corporizará no Sistema de Informação Organizacional (SIO) a gerir no quadro do SGIAP.

Se na nossa investigação, e no que respeita à primeira e segunda caraterísticas do Modelo SIAP, encontramos a sua fundamentação na abordagem realizada em torno dos paradigmas, conceitos operatórios e método de investigação adotados, as restantes caraterísticas emergem em torno da ferramenta interpretativa que integra o dispositivo metodológico identificado para a $\mathrm{Cl}$, isto é, a Teoria Sistémica e o conceito de "Sistema" que, com o Modelo SIAP, corporizam o binómio teoria/modelo em referência.

Relembramos aqui a pista de investigação que Silva suscitou a propósito da dualidade de modelos (os sistémico-informacionais, em que se insere o SIAP, e os organizacionais), e da possível modelação nessa dupla perspetiva, nomeadamente para aferir "[...] se o genuíno "espírito" do SIAP comporta incursões pelo plano estritamente de gestão e de (re)configuração 
organizacional" (SILVA, 2010, p. 3), dúvida que afirmamos partilhar pois na investigação que tínhamos em mãos afirmava-se crescentemente uma modelação pluridimensional que vai além das Entidades que integram a primeira formulação do Modelo, os Agentes/Atores, a Organização (e no seio desta a GI), e o SIAP (o Sistema de Informação [Ativa e Permanente] materialização do "negócio").

É aqui que, ao considerar que o Sistema se torna uma unidade na multiplicidade dos seus componentes, perdendo estes a sua individualidade mas tornando-se essenciais para a formação da unidade há que evidenciar a dinâmica inerente aos elementos/componentes, partes do Sistema que emergem e evoluem no contexto do todo unitário pois não se encontram, de facto, diluídos mas em permanente interação requerendo a possibilidade de perspetivação por Componente, no conjunto do Sistema unitário de que fazem parte, numa possível relação de supersistema e sistemas específicos (partes componentes).

Teremos, assim, no todo sistémico modelado através do SIAP, três elementos/componentes que contribuem para o sistema unitário, não se diluindo no mesmo:

- o Sistema Institucional/Organizacional (missão, estrutura e modelo de Gestão);

- o Sistema de Informação (fenómeno infocomunicacional humano e social);

- o Sistema Tecnológico de Informação (os Ssl e, nestes, as TI).

Os dois primeiros componentes e a relação que se estabelece entre eles é de natureza fundacional, sendo o terceiro, e consequentes relações com os anteriores, o resultado do imperativo de um meio ambiente e contextos que tornam a tecnologia omnipresente na ação Institucional/organizacional e, sobretudo, torna a génese e fluxo infocomunicacional indissociável da plataforma tecnológica que o suporta (hardware e software).

Estando subjacente a esta modelação a abordagem ao fluxo infocomunicacional pela via da Gl, esta constatação conduz a uma outra necessidade de reapreciação do modelo por forma a tornar explícitos os conceitos modelados e que, no seu agrupamento e relações identificam e caraterizam a matriz de análise científica e de operacionalização.

Neste sentido, é de considerar a constituição de conjuntos de variáveis, passíveis de representação em eixos horizontais que se interpenetram com os três componentes enunciados, desde logo ao nível informacional (organicidade, funcionalidade e memória) e ao nível circunstancial/contexto (ambiente, contexto, situação).

A valorização do quadro de relações sistémicas que está subjacente à ação social e humana e, consequentemente, à génese e fluxo infocomunicacional e às tecnologias que os suportam, tem, também, que se refletir na modelação quer entre componentes, quer entre estes e os conjuntos de variáveis tendo em mente que a diferença de posicionamentos e abordagens científicas e/ou aplicadas não se fundamenta apenas ao nível da enunciação das dimensões, eixos, componentes ou variáveis dos modelos construídos/utilizados mas, sobretudo, pelas relações que se estabelecem entre elas e que acabam por criar os "traços identitários" do caso/problema em estudo/em foco.

Por sua vez a questão da identidade/especificidade completa-se com a especificação de um conjunto de variáveis identitárias que emergem da sua Missão e Valores (cultura) da entidade/sistema em foco e da especificação do objeto de estudo e de uma abordagem em função das suas propriedades, que, em GI, faz ressaltar ao nível das propriedades da informação a estruturação pela ação (humana e social, individual e/ou coletiva), a integração 
dinâmica (contexto do sujeito da ação) e a pregnância (enunciação) da ação fundadora e da modelação informacional que delas decorre (SILVA e RIBEIRO, 2002, p. 38-43).

Teremos, assim, uma modelação que vinda a compreensão e identificação dos componentes/elementos interrelacionados envolvendo o plano infocomunicacional, o plano institucional/organizacional e da gestão organizacional, sob o impulso e não esquecendo o plano tecnológico, colocando o foco no binómio Teoria Sistémica-Modelo SIAP, peças fundamentais do Pólo Teórico do Método Quadripolar.

Focando a instituição Universidade, numa perspetiva diacrónica e sincrónica, este posicionamento permite assumir a GI de uma forma holística e sistémica, analisando o sistema de informação organizacional, o todo informacional, com o suporte garantido pelo sistema tecnológico de Informação, no todo social e no processo histórico.

Atende-se à Instituição, à sua natureza jurídica, estruturação, e consequentes re(construções) sistémicas, nomeadamente ao nível do sistema jurídico-administrativo que regula o seu funcionamento, do Sistema Educativo e do Sistema Científico, e considera-se o funcionamento organizacional e modelo de gestão, muito particularmente nas repercussões que provocam no SIO e no modelo (ou na sua inexistência) que suporta a GI, esta cada vez mais sob a pressão dos domínios científicos ligados à "Gestão" e às "Organizações", enquanto, a montante, ocorre o impacto na estrutura organizacional, atores, processos organizacionais e plataformas tecnológicas.

O confronto com esta realidade complexa e dinâmica, bem como os desenvolvimentos ao nível da reflexão teórica e aplicada e da especificação concetual em $\mathrm{Cl}$ produzida nos últimos anos, a par dos desafios/resultados entretanto obtidos ao nível da fase de investigação-ação que desenvolvemos, conduziram-nos à estruturação de uma Matriz de Análise que complementasse o modelo SIAP evidenciando os aspetos anteriormente descritos, nomeadamente as inter-relações sistémicas.

A que designámos por Matriz de Análise Sistémica (Figura 4) é constituída por Componentes e conjuntos de Variáveis de análise passíveis de aplicação à investigação de casos/problemas numa perspetiva Cl (PINTO, 2015, p. 612).

Figura 4 - Matriz/Cubo de análise (Componentes e Variáveis em contexto institucional/organizacional) 


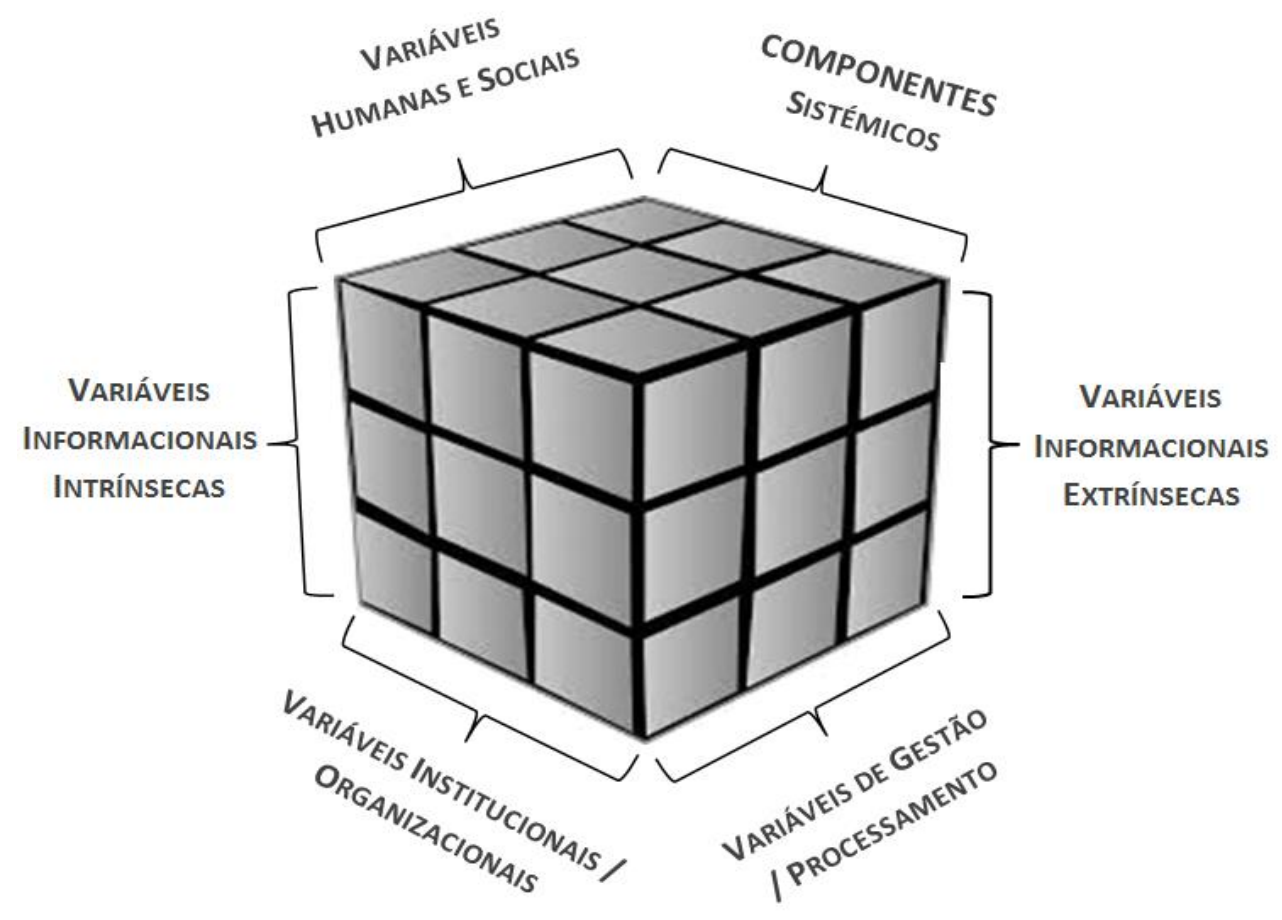

Os Componentes correspondem aos três eixos verticais fundamentais que a representação do SGIAP já evidencia: o Sistema Institucional/Organizacional (Humano/Social), o Sistema de Informação (fluxo infocomunicacional e a sua materialização) e o Sistema Tecnológico de Informação (TI/SsI).

As Variáveis estão estruturadas em conjuntos que refletem os conceitos operatórios do domínio considerados relevantes para a abordagem ao fenómeno infocomunicacional e na análise do fluxo infocomunicacional em contexto institucional/organizacional. São interatuantes e necessitam ser mantidas em equilíbrio.

$\mathrm{Na}$ abordagem inicial optou-se por uma representação de raiz unidimensional, à semelhança da proposta de Maes (1999), no entanto a representação da Matriz teve de evoluir para uma representação sob a forma de um Cubo de Análise, por forma a responder à complexidade do objeto de estudo e dar inteligibilidade às relações que se estabelecem entre COMPONENTES e VARIÁVEIS, que, de facto, constituem o "core" identitário que cada investigação/problema/caso determinará em função do caso/problema, percurso e objetivos que venha a estabelecer e que, desde logo, demarca o próprio posicionamento da investigação em $\mathrm{Cl}$, face a outros campos científicos.

Consideraram-se não três mas quatro conjuntos de variáveis, tendo-se especificado, no conjunto informacional, variáveis intrínsecas à informação (propriedades em foco) e extrínsecas (relacionadas com a sua produção, fluxo e uso) e distinguido entre variáveis de aplicação geral e variáveis de aplicação especifica, dependendo do caso em estudo:

1. Variáveis de aplicação geral:

\section{a. Informacionais}

i. Intrínsecas: propriedades da informação.

Conjunto de propriedades em foco: estruturação pela ação, integração dinâmica e pregnância; 
ii. Extrínsecas: organicidade (reflexo do ambiente, contexto, estrutura e ação produtora), funcionalidade (reflexo da cultura, comportamentos e necessidades) e memória (evidência da ação, ativo estratégico e patrimonial);

Conjunto fundamentador formulado por Silva e outros (1999) no âmbito do Sistema de Informação Organizacional (SIO);

b. Sociais / Humanas: ambiente, contexto e situação.

Conjunto em que se situa o enquadramento social e humano da ação da estrutura produtora e que emerge da formalização dos conceitos operatórios condensados por Silva (2006), sendo fundamental para abordar e compreender a ação estruturante da Instituição / Organização, o fenómeno infocomunicacional em que se materializa e, consequentemente, a sua gestão;

c. Gestão / Processamento: Estrutura/pessoas, Processos/fluxos e Tecnologia.

Conjunto cuja primeira formulação ocorre nesta tese mas que "informalmente" nos vem acompanhando desde os primeiros estudos em $\mathrm{Gl}$ refletindo o vetor da Gestão.

2. Variáveis de aplicação específica: Institucionais/Organizacionais

(na Universidade: Ensino, Investigação e Disseminação do conhecimento)

Conjunto de variáveis identitárias que corporizam a especificidade do caso em estudo, ao nível cultural, social e humano e espelham a sua missão, valores, comportamentos, práticas e, consequentemente, competências estratégicas ${ }^{27}$.

Com esta Matriz de análise sistémica completa-se o conjunto de dimensões orientadoras da operacionalização da investigação, isto é, ao nível do posicionamento científico (assumir a $\mathrm{GI}$ na perspetiva em $\mathrm{Cl}$ ), do foco informacional que a GI convoca (génese e fluxo informacional), do modelo teórico-metodológico (percurso investigativo, Modelo SIAP e Matriz de Análise sistémica).

Relativamente à Gl objetiva-se o seu foco na ação e interação que se estabelece ao nível e entre os componentes e os elementos dos diversos conjuntos de variáveis, sendo corporizada nos processos e subprocessos de GI (PINTO, 2015, p. 851-889) que identificámos e que são desenvolvidos nos diferentes "blocos" e ao longo dos níveis em que estes se estruturam ${ }^{28}$.

\section{Considerações Finais}

As mudanças impostas pela mediação das plataformas digitais exigem um novo olhar sobre o objeto a estudar/gerir/preservar e a adequação a novos modelos de atuação, cientificamente fundamentados.

\footnotetext{
27 Ao nível da Universidade chamamos a atenção para dois trinómios: a da sua Missão (ensino, investigação e serviço à comunidade) e, relacionada com esta, a corporizada no Modelo da Tripla Hélice de Etzkowitz, constituído por três vetores: Governo, Empresas e Universidade.

${ }^{28}$ Cf. representação do sistema de governança institucional e organização da Universidade do Porto (PINTO, 2015, p. 885).
} 
$\mathrm{Na}$ nossa investigação trabalhámos esta problemática tendo como foco a Universidade, que abordamos numa dupla faceta sistémica e, consequentemente, complexa, isto é, entre o sistema organizado formal e o sistema combinatório de feição loosely coupled (WEICK,1976), e a formulação de uma proposta teórico-metodológica e de modelação operacional que convergem para a definição de Gl a que chegámos, consistindo esta:

[...] no estudo, conceção, implementação e desenvolvimento dos processos e serviços inerentes ao fluxo infocomunicacional, permitindo a construção de modelos de operacionalização de máxima eficiência e rentabilização (PINTO, 2015, p. 547).

Aplicando a matriz de análise à Universidade e ao nível da componente institucional/organizacional e modelo de gestão identificaram-se, entre outros aspetos, o sistema organizado sustentado na estrutura hierárquica formal e regras que decorrem do Regime Jurídico das Instituições de Ensino Superior (RJIES) e o "loosely coupled system" de base combinatória, no qual os atores individuais desenvolvem coletivamente relações sustentadas em interpretações comuns do(s) contexto(s) para, em seguida, agir com base nesta interpretação, contribuindo e convocando sucessivamente para a cultura, o quadro de valores, os comportamentos e as práticas da Instituição secular, não prescindindo a compreensão do sistema de informação organizacional de qualquer um dos dois, pois se um confere estrutura à ação o outro confere sentido à informação.

Na proposta desenvolvida para a Universidade com base no Modelo de Gestão do Sistema de Informação Ativa e Permanente - MGSI-AP - (PINTO, 2015) tivemos em conta a complexidade e pluridimensionalidade dos vetores em análise, isto é os componentes sistémicos e os grupos de variáveis (aqui expostos) e, ainda, as dimensões, os processos e os serviços de $\mathrm{Gl}$ que, também, integram o modelo.

A sua implementação passa, naturalmente, pela tecnologia, e pela garantia de interoperabilidade do(s) sistema(s), respondendo a evolução tecnológica com uma cada vez maior eficácia e eficiência, seja através de um sistema de gestão in situ, isto é, no sistema de produção, seja de um sistema in app, isto é, que acumula a função de suporte à produção e à gestão da informação e que, não colocando em causa os serviços de informação organicamente constituídos, apresenta uma base para um olhar sistémico e para a gestão integrada de serviços e do sistema de informação organizacional.

\section{Referências}

ARÉVALO JORDÁN, Victor Hugo. La Archivología y la teoría de sistemas. Cuadernos: Archivologia, Santa Fe, v. 1, n. 1, p. 1-10, 1987.

BERTALANFFY, Ludwig von. General System Theory: Foundations, Development, Applications. Harmondsworth: Penguin,1973. ISBN: 0140600043. 
BORGES, Maria Manuel. A esfera: comunicação académica e novos media. Coimbra: Faculdade de Letras. Universidade de Coimbra. 2006. Tese de Doutoramento em Letras, área de Ciências Documentais (Tecnologia da Informação). [Em linha - só o registo]. [Acedido 30 ago. 2017]. Disponível em www:<uri:http://hdl.handle.net/10316/8557>.

BUSTELO, Carlota. Beneficios de la implantación de la UNE ISO 30300. Jornada Técnica La norma UNE ISO 30300: Aplicaciones en las empresas. Barcelona: Generalitat de Catalunya Departament de Cultura, 2012.

CARVALHO, João Álvaro. Information system? Which one do you mean? In: ISCO 4, Leiden, 1999. Information systems concepts: an integrated discipline emerging: IFIP TC8/WG8: proceedings... Ed. by Eckhard Falkenberg, Kalle Lyytinen, Alexander Verrijnstuart. Boston: Kluwer Academic Publishers, 2000. p. 259-280.

CHIAVENATO, Idalberto. Administração nos novos tempos. 2. ed. Rio de Janeiro: Editora Campus, 1999.

DeltCl: Dicionário Eletrónico de Terminologia em Ciência da Informação [Em linha]. [Consult. 15 ago. 2011]. Disponível em www: <url: https://paginas.fe.up.pt/ |ci/index.php/1668>.

DEVLIN, Keith. Info-senso: como transformar a informação em conhecimento. Lisboa: Livros do Brasil, 2000. ISBN 972-38-1733-0

ELLIS, Judith. Compliance to Recordkeeping Standards: An Overview. Transformation of Records Management Environment in the Public Sector. Embracing an e-Environment Work Culture. 2012.

GAVINA, Ana Sofia Pereira. Da Gestão de Documentos ao Sistema de Gestão de Informação Ativa e Permanente: o caso do iPortalDoc. Porto: Faculdade de Engenharia. Universidade do Porto. 2014. Dissertação de Mestrado (Ciência da Informação). Orientadora FEUP Maria Fernanda Martins; Coorientadora FEUP Maria Manuela Pinto, 2014.

GAVINA, Ana Sofia Pereira; PINTO, Maria Manuela. A redefinição da Gestão Documental: uma perspetiva em Ciência da Informação. In: VAQUINHAS, Nelson; CAIXAS, Marisa; VINAGRE, Helena. Da produção à preservação informacional: desafios e oportunidades. (p. 251-269). Évora: CIDEHUS - Centro Interdisciplinar de História, Culturas e Sociedades da Universidade de Évora. [Consult. 30 ago. 2017]. Disponível em www: <url:http://books.openedition.org/cidehus/2720>. 
INTERNATIONAL ORGANIZATION FOR STANDARDIZATION. ISO 16175:2010. Information and Documentation Principles \& functional requirements for records in electronic office environments.

INTERNATIONAL ORGANIZATION FOR STANDARDIZATION. ISO 30300:2011. Information and documentation - Management systems or records - Fundamentals and vocabulary.

INTERNATIONAL ORGANIZATION FOR STANDARDIZATION. ISO 30301:2011. Information and documentation - Management systems or records - Requirement.

JARDIM, José Maria. Sistemas e políticas públicas de arquivos no Brasil. Niterói, RJ: Editora da Universidade Feferal Fluminense, 1995.

JIMENEZ, Joan Antoni. Arxivers-gestors de documents, uns professionals per les ISO $30300 \mathrm{i}$ 30301. In JORNADA TÉCNICA, Barcelona, 2012. La norma UNE ISO 30300: aplicaciones en las empresas. Barcelona: Generalitat de Catalunya Deparatment de Cultura, 2012.

MAGALHÃES, Andreia Manuela Vieira. Gestão da Informação e dispositivos móveis : um caso de aplicação. Porto: Faculdade de Engenharia. Universidade do Porto. 2014. Dissertação de Mestrado em Ciência da Informação.

MAES, R. A generic framework for information management. PrimaVera Working Paper 9903. [Em linha]. Amesterdão: Universidade de Amesterdão, 1999. [Consult. 10 jul. 2012]. Disponível em www: <url:http://imwww.fee.uva.nl/ maestro/PDF/99-03.pdf>

MASSON, Sílvia Mendes. SIMAP - Sistema de informação municipal ativa e permanente: SIMAI - Sistema de informação municipal ativa de Indaiatuba. In Homenagem ao Professor Dr. José Marques 26 e 27 de Junho 2003: atas do Colóquio "Do Documento à Informação" e da Jornada sobre Sistemas de Informação Municipal; Memória do Curso de Especialização em Ciências Documentais (1985-2003). Porto: Faculdade de Letras da Universidade do Porto / Departamento de Ciências e Técnicas do Património / Secção de Ciências Documentais, 2004. p. 175-199.

MASSON, Sílvia Mendes; SILVA, Armando Malheiro da. Uma abordagem sistémica da informação municipal: o projecto SIMAP e um caso de aplicação ainda incipiente - o SIMAI. Cadernos de Estudos Municipais, Braga, v. 14/16, p. 33-62. 2001. 
MCKEMMISH, Sue; WARD, Nigel. Describing Records in Context: the Recordkeeping Metadata Schema (RKMS). [Em linha]. [Consult. 26 Jun. 2007]. Disponível em <www:url:http://www.archiefschool.nl/docs/rkmsdesc.pdf>

MELLA, Piero. Dai Sistemi al pensiero sistémico: per capire i sistemi e pensare com i sistemi. Milano: Franco Angeli, 1997.

MELO, Luiza Baptista. Avaliação do desempenho das Bibliotecas da Universidade do Porto : modelo de atuação. 2005 Dissertação de Mestrado em Arquivos, Bibliotecas e Ciência da Informação, Universidade de Évora, Évora.

MELO, Luiza Baptista. O Impacto das Fontes Electrónicas de Informação no Ensino Superior em Portugal. 2012. Tese de Doutoramento em Ciências da Informação e Documentação, Universidade de Évora, Évora.

MOLINA CAMPOS, Enrique. Teoría de la biblioteconomía. Ed. postuma a cargo de Rafael Olivares. Granada: Universidad de Granada, 1995. ISBN 84-338- 2116-4.

OLIVEIRA, Hugo Azevedo. A Preservação da Informação : um contributo para a implementação de um Arquivo Digital Certificável no Município do Porto. Porto: Faculdade de Engenharia da Universidade do Porto, 2014. Dissertação de Mestrado em Ciência da Informação.

PINTO, Maria Manuela; SILVA, Armando Malheiro da. Um modelo sistémico e integral de gestão da informação nas organizações. In CONTECSI - CONGRESSO INTERNACIONAL DE GESTÃO DA TECNOLOGIA E SISTEMAS DE INFORMAÇÃO, 2ㅇ, São Paulo, 2005. Actas do congresso. [CD-ROM]. São Paulo : TECSI-FEA-USP, 2005. [Em linha]. [Consult. 18 ago. 2012]. Disponível em www: $<$ http://www.tecsi.fea.usp.br/pastcontecsi/index.php/contecsi/article/view/645>.

PINTO, Maria Manuela. Gestão de Documentos e meio digital : um posicionamento urgente e estratégico. In CIANCONI, Regina de Barros; CORDEIRO Rosa Inês de Novais; MARCONDES, Carlos Henrique, (Org.). Gestão do conhecimento, da informação e de documentos em contextos informacionais. Niterói : PPGCI/UFF, 2013. (Coleção Estudos da Informação, 3).

PINTO, Maria Manuela. Gestão integrada do Sistema de Informação Municipal. Páginas a\&b: arquivos \& bibliotecas, Lisboa, v. 12, p. 91-109, 2003. 
PINTO, Maria Manuela. Information Management: a Systemic Model. Archives \& Social Studies: A Journal of Interdisciplinary Research, Cartagena, v. 1, March 2007.

PINTO, Maria Manuela. Modernização Administrativa e Qualidade: uma ferramenta chamada CAF. Cadernos BAD, Lisboa, v. 2, p. 66-77, 2004.

PINTO, Maria Manuela. PRESERVMAP: Um roteiro da preservação na era digital. Porto : Edições Afrontamento; CETAC.Media, 2009. (Colecção CAI; 7).

PINTO, Maria Manuela. Uma era, uma visão, um paradigma : da teoria à prática. Revista da Faculdade de Letras: Ciências e Técnicas do Património, Porto, 1a s, v. 4, p. 101-123, 2005.

PINTO, Maria Manuela. A Gestão da Informação nas Universidades Públicas Portuguesas : Reequacionamento e proposta de modelo. Porto: Faculdade de Letras da Universidade do Porto. Departamento de Comunicação e Artes da Universidade de Aveiro. 2015. Tese de Doutoramento em Informação e Comunicação em Plataformas Digitais.

RIBEIRO, Fernanda. Gestão da informação no sistema de arquivo da Universidade do Porto. In CONFERÊNCIA SOBRE ARQUIVOS UNIVERSITÁRIOS, Porto, 1997. Conferência sobre arquivos universitários. Porto: Universidade do Porto. Faculdade de Letras, 1999. p. 5-11.

RIBEIRO, Fernanda. Informação: um campo uno, profissões diversas? In: CONGRESSO NACIONAL DE BIBLIOTECÁRIOS, ARQUIVISTAS E DOCUMENTALISTAS, 8, Estoril, 2004. Nas encruzilhadas da Informação e da Cultura: (re)inventar a profissão: actas. Lisboa: BAD, 2004. Disponível em: <http://ler.letras.up.pt/uploads/ficheiros/artigo4181.pdf>.

RIBEIRO, Fernanda; FERNANDES, Maria Eugénia Matos. Universidade do Porto : estudo orgânico-funcional: modelo de analise para fundamentar o conhecimento do Sistema de Informação Arquivo. Porto: Reitoria da Universidade, 2001.

SILVA, Armando Malheiro da. A Informação: da compreensão do fenómeno e construção do objeto científico. Porto: CETAC.COM; Edições Afrontamento, 2006.

SILVA, Armando Malheiro da. Ciência da Informação e Sistemas de Informação: (re)exame de uma relação disciplinar. [Em linha]. PRISMA.COM, Porto, v. 5, p. 2-47, dez. 2007. [Consult. 30 ago. 2017]. Disponível em www: <url:http://www.repositorioaberto.up.pt/bitstream/10216/26180/2/000106382.pdf>. 
SILVA, Armando Malheiro da. Modelos e modelizações em ciência da informação : o modelo eLit.pt e a investigação em literacia informacional. [Em linha]. PRISMA.COM, Porto, v. 13, 2010. [Consult. 30 ago. 2017]. Disponível em www:

<url:http://revistas.ua.pt/index.php/prismacom/article/view/785/710>

SILVA, Armando Malheiro da. O impacto do uso generalizado das TIC (Tecnologias da Informação e Comunicação) no conceito de documento : ensaio analítico-crítico (I). PRISMA.COM, Porto, v. 16, p. 1-61, 2012.

SILVA, Armando Malheiro da. [et al.] Arquivística: Teoria e prática de uma ciência da informação. 2. ed. Porto: Afrontamento, 1999.

SILVA, Armando Malheiro da; RIBEIRO, Fernanda. Das "ciências" documentais à ciência da informação: ensaio epistemológico para um novo modelo curricular. Porto: Edições Afrontamento, 2002.

SOUSA, Paula Maciel Carvalho de. Segurança e preservação da informação: um modelo para os Municípios. Porto: Faculdade de Engenharia. Universidade do Porto, 2013. Dissertação de Mestrado em Engenharia de Serviços e Gestão.

TERRA, Ana Lúcia. As Políticas de informação e de comunicação da União Europeia : uma leitura diacrónica e exploratória no âmbito da Ciência da Informação. Coimbra: Faculdade de Letras da Universidade de Coimbra, 2008. Tese de Doutoramento. (Doutoramento em Letras, Ciência de Informação Arquivística e Biblioteconómica, especialidade Gestão da Informação e de Serviços de Informação).

WEICK, Karl. Educational Organizations as Loosely Coupled Systems. Administrative Science Quarterly, v. 21, p. 1-19, 1976. 